\title{
Krebs im Medienzeitalter
}

Das Thema Krebs lässt niemanden kalt. Auch im Zeitalter der Hightechmedizin ist die Diagnose einer Krebserkrankung eine tiefe Zäsur im Leben der Betroffenen. Wo die eigene Existenz bedroht ist, lassen sich existenzielle Fragen nur noch schwer verdrängen. Das Bewusstsein der Endlichkeit des Lebens, das neben Dutzenden von überaus wichtigen Projekten, Plänen und Hoffnungen auch noch irgendwo in unserem Geist ein Schattendasein fristet, rückt unversehens mit einer Klarheit in den Vordergrund, die kein Ausweichen mehr zulässt. «Wieviel Zeit bleibt mir?» ist eine manchmal sehr indirekt gestellte - Frage, mit der sich Ärztinnen und Ärzte im Gespräch mit Krebspatienten fast immer konfrontiert sehen.

Während sich das Gewicht der Diagnose Krebs für das betroffene Individuum in den letzten Jahrzehnten trotz verbesserter Therapieoptionen nicht wesentlich verändert haben dürfte, hat das Informations- und Medienzeitalter die Perzeption der Erkrankung in der breiten Öffentlichkeit entscheidend beeinflusst. Das hat wohl seine guten Seiten. Wenn erfolgverwöhnte Popstars, Politikerinnen und Direktorinnen es «dank» Brustkrebs auf die Titelseiten nicht nur der Boulevardpresse schaffen, kann dies dazu beitragen, solche Krankheiten von Assoziationen wie Versagen, Schuld oder Scham zu entkoppeln. Die Kehrseite der Medaille liegt unter anderem im Umstand, dass die Medialisierung wiederum die Gefahr einer Dichotomisierung in «Winner» und «Loser» fördert. Quoten und Auflage - und das, machen wir uns nichts vor, ist das Mass der Dinge - bringt in erster Linie das Extreme. Da es auch der ständig neue Tiefstmarken erreichende ethische Pegelstand der breiten Publikumsmedien (noch) nicht erlaubt, Zerfall und Sterben als Show zu inszenieren, finden vorwiegend diejenigen ein Forum, die ihren Krebs «besiegt» haben. Die Ausnahme von der Regel sind natürlich die Prominenten, für die auch im Krankheitsfall deutlich härtere mediale Regeln gelten als für die Durchschnittsbevölkerung.

Öffentlich-rechtliche Fernsehanstalten haben bei schwierigen Themen wie Krebs gegenüber Privatsendern Vorteile, da sie weniger um die Publikumsgunst buhlen müssen. Dass sie ihre Chancen mitunter nutzen, zeigte sich im laufenden Internationalen Monat des Brustkrebses bereits mehrfach. Noch vor einigen Jahren wurden in Sendungen wie dem damaligen Club II des österreichischen Fernsehens eine umstrittene Reizfigur wie der deutsche «Krebsarzt» Ryke
Geerd Hamer (dem 1986 die Zulassung als Arzt entzogen wurde) und seine «orthodoxen» Kontrahenten wie Gladiatoren aufeinander losgelassen. Inzwischen scheint man gelernt zu haben, dass solche medialen Schaukämpfe für Betroffene ein unwürdiges Schauspiel und für die Sache sinnlos sind. Ausgerechnet das vielgescholtene Schweizer Fernsehen SF1 ist in diesem Monat mit zwei guten Beispielen vorangegangen.

Das zurückhaltende Konzept der Sendung «Puls» vom 2. Oktober erwies sich als ausserordentlich geeignet für eine angemessene Auseinandersetzung mit der schwierigen Thematik Brustkrebs. Der gewählte Rhythmus, geprägt durch eher kurz aufeinanderfolgende Wechsel zwischen Aussagen betroffener Frauen, Interviews mit Experten im Studio sowie Einspielungen von Sequenzen zur Pathophysiologie und Therapie der Erkrankung, machte zwar Konzessionen an die Sehgewohnheiten eines jüngeren Publikums, pendelte sich aber insgesamt stimmig zwischen Hektik und Langatmigkeit ein. Die Informationen erfolgten verständlich, sowohl in den Filmbeiträgen als auch seitens der anwesenden Experten, die zudem eine hohe Sozialkompetenz ausstrahlten. Beeindruckend das untrügliche Gespür der interviewten Frauen für die Schwachstellen einer Kampagne, die die therapeutischen Fortschritte der letzten 10 Jahre mit einem in mancher Hinsicht fragwürdigen Plakat herausstrich.

Eine ähnlich positive Bilanz kann bezüglich des «Club» vom 3. Oktober gezogen werden. Auch hier keine publikumswirksame kontradiktorische Runde, in der das eigene Glaubensbekenntnis rezitiert und ansonsten aneinander vorbeigeredet wurde, sondern Fachleute und Patientinnen, die einander zuhörten und gemeinsam zentrale Aspekte des Themas herausarbeiteten. Als sich bei der Frage des Mammographiescreenings andeutete, dass Konfliktpotential selbst unter Experten mit derselben Grundausrichtung vorhanden ist, wurde unmittelbarer ersichtlich, wie schnell ein Abdriften ins Polemische die Substanz einer Sendung aushöhlen kann.

Interessanterweise blieben in beiden Sendungen - beabsichtigt oder nicht - Sterben und Tod weitestgehend ausgeklammert. Angesichts der 1400 Frauen, die jährlich in der Schweiz an den Folgen einer Brustkrebserkrankung sterben, könnte eine behutsame mediale Annäherung an diese unverändert tabuisierten Zonen ein verdienstvolles Unterfangen sein.

Bruno Kesseli 